\title{
COMUNITARISMO VERSUS LIBERALISMO. ESTADO DE LA CUESTION
}

María Elósegui Itxaso*

Ante el tema constituye necesidad de fuerza mayor apuntar los últimos avances y progresos en el debate liberalismo-comunitarismo. ${ }^{1}$

El presente artículo pretende llamar la atención sobre la riqueza e interés del mismo, remitiendo a la bibliografia más reciente.

La aparición en los dos últimos años de obras como las de Rawls, ${ }^{2}$ Dworkin ${ }^{3}$ y Habermas, ${ }^{4}$ que prestan una indudable atención a las críticas y propuestas comunitaristas precisan de un proceso de asimilación y de reflexión serena.

* Profesora titular de Filosofia del Derecho, Universidad de Zaragoza.

1 Quiero dejar constancia de mi deuda con Guy Haarscher, profesor de la Universidad Libre de Bruselas por las discusiones mantenidas sobre este debate, en mi estancia de investigación en la Academia de Teoria del Derecho de Bruselas, durante el curso académico 93/94. Agradezco también a la entidad CAI-CONAI su apoyo financiero para la realización de la misma. Entre los testimonios de primera mano debo citar la amabilidad del profesor Charles Taylor, que me brindó su tiempo para una entrevista en la Universidad de McGill (Montréal). Por último añadir mi agradecimiento a Carlos Thiebaut por poner a mi disposición por anticipado el texto de la introducción a la traducción de la obra de Taylor, The Malaise of Modernity, y a Mª Pilar González Altable por sus comentarios a raíz de su última obra.

2 RAWLS, J. Political Liberalism. New York: Columbia University Press, 1993. GONZALEZ ALTABLE, M ${ }^{a}$ P. John Rawls. Una concepción política y liberal de la justicia. Iria Flavia Padrón, Novo Século, 1993.

3 DWORKIN, R. "Liberal Community". California Law Review, v. 77, n. 3, 1989, p. 479-504. DWORKIN, R. El dominio de la vida. Una discusión acerca del aborto, la eutanasia y la libertad individual. Barcelona: Ariel, 1994. Título original: Life's Dominion. 1993. Crr. reseña en el presente Anuario de Filosofia del Derecho, realizada por Ana Maria Marcos Del Cano. DWORKIN, R. Etica privada e igualitarismo político. Introducción de Fernando Vallespin. Traducción Antoni Domènech. Barcelona, ICE-Paidós, 1993. Original Foundations of Liberal Equality. Salt Lake City: University of Utah Press, 1990. VALLESPIN, F. Introducción a DWORKIN, R. Etica privada e igualitarismo politico, op. cit, p. 9-35. DWORKIN, R. L'aws Empire. Cambridge, Mass.: Harvard University Press, 1986. Cfr., el republicanismo cívico liberal de Dworkin en el Capitulo 6.

4 HABERMAS, J. Identidades nacionales y post-nacionales. Madrid:, Tecnos, 1989. HABERMAS, J. "Ciudadania e identidad nacional. Consideraciones sobre el futuro europeo". In: Europa, la democracia y la izquierda, Debats. n. 39, mar. 1992, p. 11-18. Texto de la conferencia pronunciada por

\begin{tabular}{l|l}
$\mathrm{n}^{2} 2$ & Junho 1998
\end{tabular}

p. $287-302$ 
Sus planteamientos no exentos de implicaciones éticas y políticas se sumergen también en los problemas propios de la Filosofia del Derecho.

En este sentido el comunitarismo como corriente de pensamiento afecta a muchos aspectos de la vida humana. En realidad es una nueva propuesta política que atañe a la organización social, cultural, política y jurídica de cualquier comunidad humana.

El comunitarismo se presenta como una alternativa a los modelos políticos tanto marxistas como liberales. Sus críticas van dirigidas al individualismo y atomización de las sociedades postindustriales. Por eso se insiste en recuperar la idea de comunidad, de la sociabilidad como algo esencial en el desarrollo de la identidad humana. Se propugna una mayor y directa participación de todos los ciudadanos en la vida pública. La res publica, los asuntos públicos deben ser resueltos entre todos. Hay que participar a nivel de pequeñas asociaciones, cada uno en nuestro entorno, asociaciones de vecinos, consejos escolares etc. Es decir se propone el fomento de un nuevo corporativismo y un mayor asociacionismo.

Entre la literatura secundaria referente a esta polémica es forzosa una referencia a la obra de Stephen Mulhall y Adam Swift, Liberals and Communitarians, imprescindible para centrar las bases del debate, y evitar que los árboles nos impidan ver el bosque..$^{5}$ El mismo Will Kymlicka, un pensador liberal certero en la exposición de este tema, ${ }^{6}$ afirma que la obra de Mulhall y Swift se define por su claridad y por la identificación de las claves de la presente polémica, distinguiendo entre lo sustancial y la retórica empleada en las partes enfrentadas.

El comunitarismo anglo-americano ha adquirido un carácter propio. Aunque en un principio surgió sin un mutuo acuerdo entre sus defensores, provenientes de distintas universidades americanas (estadounidenses - Walzer, ${ }^{7}$ MacIntyre, ${ }^{8}$ San-

Jürgen Habermas en la Facultad de Ciencias Económicas de la Universidad de Valencia el 14 de octubre de 1991. HABERMAS, J. Faktizitàt und Geltung. Beiträge zur Diskurstheorie des Rechts und des demokratischen Rechtsstaats. Frankfurt M.: Suhrkamp, 1992, 667 p. HABERMAS, J. Necesidad de revisión de la izquieda. Madrid: Tecnos, 1991. HABERMAS, J. "Tres modelos de democracia sobre el concepto de una política deliberativa". In: Europa, la democracia y la izquierda, Debats, n. 39, mar. 1992, p. 18-21.Texto de la intervención de Jürgen Habermas en el seminario sobre Teoria de la Democracia, celebrado en la facultad de Filosofia de Valencia el 15 de octubre de 1991. HABERMAS, J. "Más humildad, menos ilusiones. Una conversacion entre Jürgen Habermas y Adam Michnik". Debats, n. 47, mar. 1994, p. 59-65. HABERMAS, J. Escritos sobre moralidad y eticidad. Barcelona: ICE-Paidós, 1991.

5 MULHALL, Stephen, SWIFT, Adam. Liberals \& Communitarians. Oxford UK \& Cambridge, USA, Blackwell, 1992. Stephen Mulhall es Reader de Filosofia en la Universidad de Essex y Fellow en All Souls College de Oxford. Adam Swift es Fellow y Tutor en Filosofia política y sociologia en Balliol College, Oxford.

6 KYMLICKA, W. Liberalism, Community and Culture. New York, Oxford Clarendon Press, 1991. Primera edición (1989).

7 WALZER, M. Exodus and Revolutio. Basic Books, 1985. WALZER, M. Interpretation and Social Criticis. Harvard University Press, 1987. WALZER, M. "La idea de sociedad civil. Una vía hacia la reconstrucción social”. Debats, n. 39, 1992, p. 30-39. Michael Walzer nace en Nueva York en 1937. Está considerado en la actualidad como uno de los teóricos más importantes de la izquierda intelectual no dogmática de Estados Unidos. Ha sido profesor de ciencias sociales en las universidades de Princeton y Harvard. Desde 1980 enseña en el Institute for Advanced Study (School of Social Science) de Princeton, New Jersey. WALZER, M. Spheres of justice. A defense of pluralism and equality. New York: Basic Books, 1983. WALZER, M. "The communitarian Critique of Liberalism". Political Theory, v. 18, n. 1, 1990, p. 6 y ss. WALZER, M. The Company of Critics. Basic Books, 
del $^{9}$ - y canadienses), en la actualidad ha aglutinado elementos comunes con los que todos ellos se ven identificados. ${ }^{10}$

Así el propio Charles Taylor ${ }^{11}$ me declaró en el transcurso de una entrevista; "En realidad el témino comunitarismo es aplicable a pensadores muy diferentes como Sandel, Macintyre o yo mismo. Considero el comunitarismo como un tipo de liberalismo entre otros. Se inserta en la tradición del pensamiento de Tocqueville, que fue un pensador liberal. Lo que nos aúna es la crítica del liberalismo estándar. Este factor hace que se considere el comunitarismo como un bloque, aunque nuestra crítica se hace desde posiciones muy diferentes, desde la izquierda y desde la derecha". 12

Mulhall y Swift situán las críticas del comunitanismo al liberalismo tomando como referente la filosofía politica de Rawls. Consideran que fue precisamente la aparición de A Theory of Justice el detonante de las primeras críticas antiliberales, que con el transcurrir del tiempo, se constituirian como alternativa comunitarista. Además este intento de presentación sintética cobra realce porque tiene en cuenta la evolución del pensamiento rawlsiano en los diferentes artículos escritos en la década de los años ochenta. Es cierto que la aparición de la última obra rawlsiana, Political Liberalism, se produce un año más tarde. No obstante el mis-

1988. KALLSCHEUER, O. "EI liberalismo comunitario de Michael Walzer. La fuerza de la oposición interna". Debats, n. 39, 1992, p. 40-45.

8 MACINTYRE, A. After virtue. Notre Dame: University of Notre Dame Press, 1981. Traducción española por Amelia Valcárcel: Tras la virtud. Barcelona: Critica, 1988 y MACINTYRE, A. Whose justice? Which Rationality? Notre Dame: University of Notre Dame Press, 1988. La última obra se reseña el Anuario de Filosofia del Derecho, X, (1993). MACINTYRE, A. Three Rival versions of Moral Inquiry: Enciclopaedia, Genealogy and Tradition. Notre Dame: University of Notre Dame Press, 1990. Versión española: Madrid: Rialp, 1992, $250 \mathrm{p}$.

9 SANDEL, M. "Moral argument and Liberal Toleration: Abortion and Sexuality". California Law Review, v. 77, n. 3, 1989, p. 521-538. SANDEL, M. Liberalism and its Critics. Oxford: Basil Blackwell, 1984. SANDEL, M. Liberalism and the Limits of Justice. Cambridge: Cambridge University Press, 1982. SANDEL M. "The political theory of the procedural republic". In: HUTCHISON, Allan R., MONAHAN, P. (eds.). The rule of law. Ideal or ideology? Toronto: Carswell, 1987, p. 8596. SANDEL, M. "The Procedural Republic and the Unencumbered self". Political Theory, v. 12, Feb. 1984, p. 81-96.

10 THIEBAUT, C. Los límites de la comunidad. (Las criticas comunitanistas y neoaristotélicas al programa modemo). Madrid: Centro de Estudios Constitucionales, 1992. 221 p. THIEBAUT, C. "Recuperar la moral: la filosofia de C. Taylor. Introducción a La ética de la autenticidad de Charles Taylor, Barcelona: ICE-Paidós, 1993, 146 p. ELOSEGUI, M. Reseña sobre Los límites de la comunidad de Carlos Thiebaut. Anuario de Filosofia del Derecho. v. 10, 1993, p. 648-653.

11 TAYLOR, C. "Cross-purposes: the Liberal-Communitarian Debate". In: ROSEMBLUM (ed.) Liberalism and the moral life. Cambridge, Mass.: Harvard University Press, 1989, p. 159-182. TAYLOR, C. Sources of the self. The Making of Modern Identity. Harvard University Press. Cambridge, Mass., 1989. Hay traducción española: Origenes del yo. La construcción de la identidad moderna. Barcelona: ICE-Paidós. TAYLOR, C. La ética de la autenticidad. Introducción de Carlos Thiebaut. Barcelona: ICE-Paidos, 1993. TAYLOR, C. The Malaise of Modernity. Ontario, Canada: Anansi Press, 1991. 135 p. The Massey lectures están patrocinadas por Massey College en la Universidad de Toronto y CBC radio (Canadian Broadcasting Corporation, Société Radio-Canada). Charles Taylor es profesor de filosofia politica en la universidad de McGill de Montreal. TAYLOR, C. Multiculturalism and the politics of recognition. GUTMANN, A. (ed.), Princeton, New Jersey: Princeton University Press, 1992, con comentarios de Steven C. Rockfeller, Michael Walzer y Suasan Wolf. TAYLOR, C. Reconciling the solitudes. Essays on Canadian Federalism and Nationalism. LAFOREST, Guy (ed.) Montreal \& Kingston, London, Buffalo: McGill-Queen's University Press, 1993. ELOSEGUI, M. “Entrevista con Charles Taylor”. Debats, n. 47, mar. 1994, p. 40-46. 
mo Rawls en la introducción reconoce que todos los capítulos, con excepción de uno de ellos, han sido publicados anteriormente. ${ }^{13}$

Esta observación no es vanal porque precisamente los autores de Liberals and Communitarians mantienen la tesis de que las críticas del comunitarismo a Rawls no han quedado eliminadas a pesar de las réplicas de éste. Si bien es admisible una evolución en el pensamiento de Rawls, la cual ha ayudado a una mayor comprensión del mismo, no es posible sin embargo observar un cambio sustancial con respecto a la perspectiva adoptada en $A$ Theory of Justice. ${ }^{14}$

Sin duda, la defensa frente a sus críticos ha sido útil para que Rawls clarificara su posición en algunos puntos y para que cambiara en otros. A pesar de ello la influencia del comunitarismo ha sido mayor en Dworkin y Habermas, que se distancian cada vez más de la idea de la neutralidad y el formalismo, y se añaden al rechazo del presunto velo de ignorancia en la posición original.

Hecha la presentación de rigor, adentrémonos en los puntos que han suscitado la critica soliviantada de los comunitaristas. Los frentes de batalla se agrupan en torno a cinco tesis:

1. La concepción de la persona. El comunitarismo rechaza la concepción de la persona que se esconde o que está en la base del planteamiento liberal. El liberalismo diferencia entre la persona y sus fines o valores o concepciones del bien. Para los comunitaristas no existe la persona, como algo separado de su concepción del bien, ya que ésta es constitutiva de la identidad personal. Se debe de reconocer que la posición original sitúa la cuestión sobre las concepciones de la persona como centro del debate teórico-politico. Rawls no niega que su teoria se construye alrededor de una concepción de la persona. ${ }^{15}$

En la posición original es inevitable tener que decidir sobre qué es importante para la gente, cuáles son sus intereses, qué constituye su bienestar etc.

Rawls opta por una concepción de la persona que implica una concepción del bien. La identificación de nuestro interés más elevado parece presuponer que somos individuos libremente capaces de formar y cambiar nuestros puntos de vista sobre cómo debemos vivir nuestras vidas.

La pregunta pertinente es si realmente podemos volver hacia atrás, retroceder hacia el origen de los valores particulares que defendemos y cambiarlos por otros nuevos, o ¿no será mas bien al contrario?, que somos las personas concretas que somos debido a los valores que mantenemos.

La posición original sólo tiene en cuenta nuestra concepción sobre la justicia, pero deja de lado otras muchas cuestiones que forman parte esencial de la vida moral de las personas.

13 RAWLS, J. Political Liberalism, op. cit., Introducción.

14 Entre los estudios de Rawls realizados en ámbito español, cfr. el más reciente de $\mathrm{M}^{2}$ Pilar González Altable. Esta obra es tambiém anterior a la publicación de Political Liberalism.

15 Disiento en este punto de la interpretación de $\mathrm{M}^{\mathrm{a}}$ Pilar González Altable, pare quien Rawls no necesita y no pretende elaborar una teoria de la persona, ya que su fin es hacer una teoria política y no metafísica. Aunque esa fuera su pretensión es inevitable que la teoría política remita a la antropología, bien elaborada por el mismo Rawls o bien tomada de otras fuentes, como por ejemplo la kantiana. No se puede construir una teoria ética y politica suspendida en el aire. 
En conexión con ello se entrevé la cuestión de las distintas concepciones de la justicia que nacen de las diferencias culturales. Esa elección del valor más elevado a defender está condicionado por la cultura. No cabe tampoco una concepción de la libertad que llevara a elegir una concepción del bien.

La prioridad asignada en el liberalismo a la libertad individual, quizá sea coherente, pero indeseable porque, infundamentadamente, enfatiza un aspecto de Ia vida moral a costa de ser negligente con otros. En definitiva, el yo presupuesto por Rawls es un yo racional, al modo kantiano. ${ }^{16}$

2. En segundo lugar, los comunitaristas denuncian el individualismo asocial, presente en el liberalismo. La cuestión que surge aquí es si Rawls ofrece o no una teoria de la sociedad.

El liberalismo malentiende la relación entre el individuo y la sociedad o comunidad en la que éste se inserta. Todavía más ignora hasta que punto es la propia sociedad, en la que se halla inmerso el individuo, la que modela lo que él es y los valores que posee.

La concepción liberal parte de la hipótesis del contrato social entre indivíduos. El individualismo propugnado por Rawls intenta evitar que la mayoría utilice a los demás como medios para sus fines, es decir rechaza el utilitarismo. Pero, a pesar de ello, para los comunitaristas en este planteamiento de Rawls se presupone un individualismo asocial.

En primer lugar porque desde un punto de vista socio-filosófico el autoconocimiento y las concepciones del bien derivan de la propia matriz social. Es decir no se puede aislar la elección de una concepción de la justicia del proceso de socialización. No es posible desvincular la identidad personal de la identidad social. El descubrimiento de la primera está inexorablemente unida a los orígenes necesariamente comunales y sociales.

En segundo lugar, el liberal ve la sociedad sólo como una aventura cooperativa para el logro del beneficio individual, como una asociación esencialmente privada formada por individuos cuyos intereses se definen con independencia de la comunidad de la cual son miembros. En definitiva se desvincula la ética de la política. Se excluyen concepciones del bien que están fuertemente vinculadas a la comunidad. En último caso, se atiende a los bienes individuales, pero no a los bienes sociales, como algo que debería estar presente en ese momento en el que se elige unos criterios de justicia. El liberal no tiene en cuenta que parte de nuestra propia identidad se forma en nuestras relaciones con los otros, de ahí que en la posición original se pretende una uniformidad utópica, y se excluyen las diferencias, esenciales para respetar la existencia de una pluralidad de comunidades.

16 GONZALEZ ALTABLE, M P., op. cit., p. 196. MATSUDA, M. "La jurisprudencia liberal y visiones abstractas de la naturaleza humana. Una critica feminista a la teoria de la justica de Rawls". In: DURAN, P. (ed.), Debates sobre el género. Traducción Maria Elósegui. Castellón: Ayuntamiento de Castellón, p. 119-137. 
Esta visión del comunitarismo es lo que Rawls ha denominado concepciones o doctrinas comprehensivas, globales de la moral y de la política. ${ }^{17}$ Dworkin ha acuñado un nuevo término, éticas de impacto frente a la ética del desafio, que es la que él propugna. ${ }^{18}$

Los liberales pretenden que las distintas concepciones del bien no influyan en la comunidad política, mientras que para los comunitaristas algunas concepciones sustantivas suponen que la vida buena para los seres humanos incluye la participación en la vida política, hasta el punto de que el contenido del bienestar individual es inherentemente comunal y comunal al nivel de la sociedad política, y no sólo en la esfera privada.

El liberal concibe que en las relaciones entre el individuo y el Estado no es imprescindible la participación activa en la vida política, mientras que para el comunitarista ello es esencial. La esencia política del ser humano no es una cuestión de libre elección, sino que entra en la esfera de las obligaciones más que en la de un derecho que puede ser ejercido o no.

El liberalismo desgaja unos intereses considerados pre-sociales, de la condición de ser miembro de una sociedad.

Pero según Mulhall y Swift, no está claro que el énfasis de los liberales en las libertades individuales sea negligente con el significado de la matriz social que los comunitaristas subrayan.

Rawls ha respondido con su teoria del overlapping consensus, consenso por solapamiento, en la que se enfrenta con los problemas derivados de los fines y valores sociales; "los valores de la comunidad no son solamente esenciales sino también realizables, primero en las distintas asociaciones que desarrollan su vida dentro del armazón de la estructura básica, y segundo, en aquellas asociaciones que transcienden los límites del estado-nación, como iglesias, sociedades científicas... El liberalismo rechaza el estado como comunidad porque, entre otras cosas, ello conduce a una negación sistemática de las libertades básicas y a un uso opresivo del monopolio de la fuerza (legal) del estado. Añadiré que en la sociedad bien ordenada de justicia como equidad los ciudadanos comparten una idea común, y una que tiene una alta prioridad: a saber, la intención de la justicia política, esto es, la intención de asegurar que las instituciones políticas y sociales sean justas, "[...] como aquéllo que los ciudadanos necesitan para si mismos y desean para los otros. No es verdad, entonces, que en una visión liberal los ciudadanos no tengan unas intenciones comunes fundamentales. [...]. Pero esta intención común de una justicia política no debe ser erróneamente entendida como una concepción del bien." 19

17 GONZALEZ ALTABLE, Me P., op. cit., p. 195.

18 DWORKIN, R., Etica privada e igualitanismo politico, op. cit.

19 GONZALEZ ALTABLE, Mª P., op. cit., p. 180. RAWLS. J. "The Idea of an Overlapping Consensus". Oxford Journal of Legal Studies, v. 7, n. 1, 1987, p. 1-25. Cfr. capitulo dedicado a Rawls en MULHALL, Stephen \& SWIFT, Adam. 
3. Multiculturalismo versus universalismo. ¿Es aplicable la teoria de la justicia de Rawls a todas las sociedades, en todos los lugares y en todos los tiempos?, o ¿es más bien un modelo para una sociedad dada?

Los comunitaristas critican la pretendida universalidad del liberalismo y presentan como alternativa una propuesta multiculturalista, especialmente Charles Taylor. El liberalismo no atiende al hecho de que diferentes culturas incluyen diferentes valores y diferentes formas sociales e instituciones, y que todo ello implica unas consecuencias que deben reflejarse en la teoría política.

Por tanto, la abstracción presente en la posición original es utópica. Rawls no ha tenido en cuenta la importancia moral de las diferentes culturas, que afectan esencialmente a la propia concepción de la justicia. Para Michael Walzer y Charles Taylor la particularidad cultural es central en la comprensión de como una comunidad decida organizar su vida política.

En este sentido el comunitarismo parece un mayor defensor del relativismo moral y cultural. La razón estriba en su insistencia en la importancia de la tradición y las costumbres y en la configuración de los valores morales. Sin embargo, a la vez son los propios comunitaristas quienes califican a los liberales de relativistas. A mi juicio, este dilema y esta contradicción es dificil de superar, tanto en uno como en otro planteamiento.

De hecho, Rawls ha intentado responder a las críticas comunitaristas negando que su teoría pretenda ser universal y queriendo asimilar las culturas específicas. Aparentemente la abstracción de la teoría de Rawls parece implicar una universalidad que desprecia el contexto cultural. Pero Mulhall y Swift plantean un posible camino de solución a este dilema rawlsiano: "Por una parte existe una abstracción en relación con las posiciones sociales particulares y las concepciones particulares sobre el bien, y la teoría de Rawls implica necesariamente esto. Pero no implica necesariamente un segundo tipo de abstracción, la de separar a la gente de sus tradiciones culturales o prácticas sociales. Podría ser no sólo que la teoría de Rawls no implique este segundo tipo de abstracción, sino también que sea precisamente esta la razón por la que implica el primer tipo de abstracción. Si es nuestro particular comprensión cultural la que identifica los intereces más elevados de la gente de un modo que nos exige abstraer a partir de las concepciones particulares del bien, entonces el liberalismo de Rawls difícilmente puede ser acusado de desatender la particularidad cultural". ${ }^{20}$

En otras palabras, si nuestra propia cultura incluye el universalismo, entonces Rawls no puede ser acusado de desatender las particularidades culturales.

Algunos liberales no se identifican con el último Rawls e insisten en el universalismo como algo que es verdadero para todos con independencia de la identidad y valores culturales.

Queda claro que una idea fundamental para el comunitarismo es la defensa de la cultura particular de cada grupo social o étnico. Cada persona está enraizada en sus orígenes, en su tradición, en su pasado, en su lengua y en los valores del grupo. Taylor en su última obra, El multiculturalismo. La política del reconocimiento,

20

MULHALL, S., \& SWIFT, A., p. 21. 
aboga por una defensa de la identidad de las distintas culturas, que no deben desaparecer en la uniformidad propia de las sociedades modernas. Aún admitiendo la mezcla que producen los fenómenos de inmigración, Taylor reclama el derecho a la diferencia de cada grupo cultural. Hasta ahora ha sido positivo el reconocimiento de la universalidad de los derechos humanos y de la igualdad de todos los hombres. Pero ahora junto a eso es necesario atender a las diferencias, si queremos evitar que algunas culturas desaparezcan absorbidas por los grupos mayoritarios. Esto justifica incluso que determinadas legislaciones se propongan como objetivo el mantenimiento de determinadas lenguas y modos de vida. El ejemplo cercano que Taylor describe es el de la comunidad francófona de Quebec y los aborígenes canadienses, que a diferencia de lo que ha ocurrido en Estados Unidos, todavia mantienen sus leyes y costumbres.

Ese es uno de los motivos, entre otros, por los que Taylor afirma que las leyes no son neutrales, sino que cada grupo tiene derecho a elegir sus propias metas y sus propios valores y que estos sean avalados también por la legislación sin dejarlos a la mera elección individual. Cada individuo debe identificarse en algunos aspectos con la comunidad a la que pertenece porque su esencia es sociable. Es decir, el comunitarismo como el antiguo republicanismo, preconiza una mayor relación entre la esfera privada y la esfera pública. Así la ética individual repercutirá en el bien común y en el bienestar del grupo. Muchas conductas transcienden el ámbito privado e inciden en lo público. También se destaca la importancia de las virtudes públicas o del civismo, tanto por parte de cada ciudadano como por los profesionales de la política.

Taylor describe dos tipos de liberalismo; el primer tipo de liberalismo ("Liberalismo 1") persigue la defensa de los derechos individuales, lo cual implica la necesidad de un Estado rigurosamente neutral, es decir un Estado sin proyectos culturales o religiosos 0 , finalmente sin ningún tipo de fines colectivos, más allá de la libertad personal y la seguridad física, bienestar, y salvaguarda de sus ciudadanos. El segundo liberalismo ("Liberalismo 2") permite que el Estado se comprometa en la sobrevivencia (survival) y mejora de una nación, cultura o religión particular, o un conjunto limitado de naciones, culturas y religiones, en la medida en que los derechobásicos de los ciudadanos, que tienen diferentes compromisos 0 que ni siquiera los tienen, estén todos ellos protegidos. ${ }^{21}$

Taylor se inclina por el segundo tipo de liberalismo. Aunque no lo diga expresamente en este ensayo The Multiculturalism. The Politics of "Recognition", si lo expresa con claridad en otro escrito, "Shared and Divergent Values", sobre el federalismo canadiense, recogido en un libro titulado Reconciling the Solitudes. Essays on Canadian Federalism and Nationalism.

$\mathrm{El}$ apoyar el segundo tipo de liberalismo, en determinadas ocasiones, no impide defender a su vez la universalidad de los derechos para todos. Como comenta Walzer, para Taylor el Liberalismo 2 sobrepesa la importancia de ciertas formas de tratamiento uniformes (siguiendo una teoría fuerte de los derechos) contra la importancia de la sobrevivencia de una cultura, y opta a veces en favor de esta últi-

21 p. 99. 
ma. Pero otras veces puede optar en favor del Liberalismo 1, porque el Liberalismo 2 es opcional y una de sus opciones es optar por el Liberalismo 1.

En el caso de Québec, el gobierno opta por el Liberalismo 2 cuando reconoce su peculiaridad cultural y actúa legalmente en favor de la preservación de la cultura francesa o la cultura aborigen. Muchos gobiernos europeos se interesan por la sobrevivencia cultural de la nación y sus políticas referentes al lenguaje, historia, literatura no son neutrales. A su vez son liberales, según el Liberalismo tipo 1, porque toleran y respetan las diferencias religiosas y étnicas, otorgando a las minorías una libertad similar para organizarse como tales, expresando sus valores culturales y elegiendo su modo de vida en la sociedad civil y en sus familias.

La política del reconocimiento supone la lucha por nuestra identidad, que está estrechamente unida a nuestra cultura, porque la identidad se forja dialogicamente en conexión con los otros, depende por tanto de la sociedad. ${ }^{22}$

Taylor atribuye al liberalismo el cambio de énfasis, del honor a la dignidad entendida como una política del universalismo, que al insistir en la igualdad de todos los ciudadanos ha uniformizado los derechos, olvidando el derecho a las diferencias. En la actualidad es necesario reconocer unas veces la igualdad de derechos, pero otras se requiere insistir en una identidad peculiar. Ello justifica incluir como característica de la identidad del individuo, su identidad cultural. El "Liberalismo 1" no es capaz de apreciar las distintas culturas particulares, está ciego ante las diferencias.

Taylor ataca la idea de Dworkin expuesta en un antiguo artículo, según la cual una sociedad liberal es aquella que se niega a adoptar un punto de vista sustantivo sobre los fines vitales. ${ }^{23}$

La conclusión es que nuestras sociedades son cada vez más heterogéneas y que el Estado debe enfrentarse al fenómeno del multiculturalismo, pero no por la via de la uniformización, sino por la de legislar de acuerdo con las diferencias.

Por supuesto que las tesis de Taylor han recibido numerosas réplicas, entre las que destacan las objeciones hechas por Jürgen Habermas. ${ }^{24}$

Habermas al plantearse la unión europea parece fijarse más en el modelo estadounidense, mientras que Taylor da a entender que un federalismo al estilo canadiense justificaría mejor la integración europea de las minorías étnicas y de los países de la Europa oriental.

22 TAYLOR, C. op. cit., p. 32.

23 DWORKIN, R. "Liberalism". In: HAMPSHIRE, Stuart (ed.). Public and private morality. Cambrige: Cambridge University Press, 1978. Taylor remite en varias ocasiones al artículo de Sandel, ya reseñado, en Multiculturalism, p. 58, y en Reconciling the solitudes, p. 114.

24 THIEBAUT, C. "Democracia y diferencia: un aspecto del debate sobre el multiculturalismo". Conferencia, inédita, próxima publicación en Minnesota University Press, será incluida en la versión inglesa de Los límites de la comunidad. Alli Thiebaut comenta y analiza críticamente los seguientes articulos: HABERMAS, J. "Struggles for recognition in constitutional states", European Journal of Philosophy, v. 1, n. 2, Aug. 1993, p. 128-155. McCARTHY, Th. "Legitimacy and diversity: dialectical reflections on analytical distinctions". 1994. Mimeo. RAWLS, J. "The law of peoples". In: SHUTE and HURLEY, S. (éds.). On human rights. N. York: Basic Books, p. 41-82. Para la última obra de Habermas confróntese la reseña de GALINDO AYUDA, F. en este mismo Anuario de Filosofia del Derecho, y la de GARCIA AMADO, J. A. "La filosofia del Derecho de Jürgen Habermas", Doxa, n. 13, (1993), p. 235-258. 
Habermas ha criticado la postura de Taylor, entre otras cosas por su definición del patriotismo, tal y como se presenta en su artículo "The Liberal-Communitarian Debate", ${ }^{25}$ como una identificación común con una comunidad históricamente fundada sobre algunos valores. Para Habermas una cultura política no tiene que estar basada en un origen étnico, lingüístico y cultural, común entre los ciudadanos. ${ }^{26}$

Taylor ha respondido a este desafío de Habermas con la siguiente tesis: "una sociedad libre no puede existir sin patriotismo, a no ser que quiera ser un imperio como lo fue el austro-húngaro. En una sociedad democrática moderna no es posible desinteresarse por el propio país. Las comunidades democráticas exigen una participación deliberativa. Ciertamente, el patriotismo puede degenerar y convertirse en algo negativo, abandonando su carácter virtuoso. Sin embargo, no estoy de acuerdo con esa caracterización del patriotismo que hace Habermas, ya que es abstracta y no refleja la realidad. La Constitución en sí, no es algo capaz de obligarnos a comprometernos en la vida política. Necesitamos algo más fuerte por lo que sentirnos obligados y atraídos, y que no se exija comprometernos por un ideal. No es suficiente seguir unas reglas generales, debemos comprometernos en asuntos concretos, particulares. Por otra parte, como respuesta a la crítica de Habermas, diré que hay una dimensión del patriotismo que no tiene que estar necesariamente conectado a la raza, sino a la historia, una historia abierta. En Québec por ejemplo ha habido una evolución, una mayor apertura. Antes se tenía más en cuenta el origen étnico, ahora asistimos a una evolución que ha convertido a Québec en una sociedad más abierta". ${ }^{27}$

A pesar de las justificaciones de Taylor, ello no impide sugerir que, a mi juicio, algunas de las premisas del comunitarismo necesitarían ser equilibradas con una dosis de universalismo y cosmopolitismo. Los sentimientos de pertenencia al grupo serán positivos si se ven compensados con una dosis de racionalismo, lo contrario podría desembocar en un partidismo parcialista, que sólo vea como positivo lo del propio grupo y no sepa reconocer los valores de las demás culturas, o vea a los otros como enemigos en potencia.

El comunitarismo debe completarse con una política de inclusión, es decir que el esfuerzo por salvaguardar la propia cultura, la propia lengua, no lleve a despreciar al que no pertenece al grupo, al outsider, a quien desde fuera hace un esfuerzo por integrarse en esa comunidad, habida cuenta de que nadie ha elegido el grupo cultural al que pertenece, le ha venido dado.

A la defensa que el comunitarismo hace del patriotismo como virtud, hay que añadirle una ración de universalismo, que lleve a valorar la dignidad de cada persona por encima de las diferencias y por lo que vale en sí misma, reconociendo además que el intercambio cultural más allá de la propia comunidad contribuye al enriquecimiento de todos.

25 TAYLOR, C. "Cross-purposes: the liberal-communirarian debate". In: Liberalism and the moral life, op. cit., p. 159-182.

26 HABERMAS, J. "Ciudadanía e identidad nacional. Consideraciones sobre el futuro europeo", Debats, op. cit., p. 17-18.

27 ELOSEGUI, M. “Entrevista con Charles Taylor”. Debats n. 47, mar. 1994, p. 45. 
A la aceptación de la tradición y de los valores del grupo le falta el ingrediente de una dosis de criticismo, porque no todo lo heredado es por serlo positivo. Es decir el anclarse en el pasado y no atender a la evolución histórica y al progreso, conduce a un conservadurismo absurdo. El favorecer sólo a los del propio grupo desemboca en la corrupción y en la injusticia. Si esto se agudizara hasta podría degenerar en los racismos y xenofobias desencadenados en Europa, que todos lamentamos y que ha sido denunciados en un informe de la Comisión Europea, informe Ford. ${ }^{28}$

Sería deseable que se cumplieran los pronósticos hechos por el propio Taylor que veía que la comunidad europea era un buen foro de integración de las pequeñas comunidades, en las que se podía hacer compatible el particularismo multicultural con el universalismo cosmopolita. ${ }^{29}$

4 - El subjetivismo u objetivismo. La posición original representa un modelo en el que se prioriza o se sitúa como máximo interés para las personas su capacidad de decidir libremente, perseguir racionalmente y fundar personalmente su propia concepción del bien.

Por ello el comunitarismo se cuestiona si esta hipótesis no responde de hecho a una determinada concepción sobre las creencias y valores morales. La sospecha es que el énfasis en que es el indivíduo el que debe elegir su propio plan de vida significa que para los liberales esas elecciones son arbitrarias y expresiones de las preferencias personales.

Esa es la conclusión a la que llegan los comunitaristas. Contra ello algunos liberales, como por ejemplo Joseph Raz, defienden como compatible el ser liberal y la tesis de que los juicios sobre valores sean objetivos.

De todos modos el liberalismo no implica necesariamente una ética subjetiva, algunos pueden defender una ética objetiva, junto con la necesidad de la tolerancia, es decir respetar las distintas posturas y fomenter que los individuos descubran libremente esos valores, sin necesidad de que el estado los imponga.

Ciertamente hay motivos para pensar que en muchos casos el liberalismo y el subjetivismo moral o el escepticismo concurren. Si ningún modo de vida es mejor que otro, si las elecciones de las personas son expresiones de las preferencias, sin ninguna justificación racional de sus valores, reduciéndolos a una cuestión de gustos subjetivos, entonces el Estado se limitará a respetar las elecciones de los individuos y no estaria justificado que promoviera un tipo de vida más que otros. Una vida dedicada a alcanzar la belleza y la verdad estaría en igualdad de condiciones o equiparada a una vida empleada jugando a video-juegos. En este caso el resultado de cualquier elección, siempre que sea libre, se juzgaría en pie de igualdad. Detrás se esconde cierta vaga y escéptica creencia de que todas las elecciones son igual de buenas porque tampoco hay un criterio racional para juzgarlas. Este sería, por ejemplo, el emotivismo propio de' nuestra cultura liberal, denunciado y analizado por Alasdair MacIntyre.

28 Informe Ford, Comision de Investigación del racismo y la xenófobia. Luxemburgo. Oficina de Publicaciones oficiale de las Comunidades Europeas. 1991. Ponente Mr. Ford.

29 ELÓSEGUI, M. "Entrevista con Charles Taylor”, op. cit., p. 43. 
El liberal subjetivista cae en sus propias redes y se enfrenta con el problema de justificar racionalmente su propio liberalismo y la necesidad de apoyar un estado liberal. Es posible escapar de esa crítica diferenciando entre los juicios sobre como la gente debe vivir su vida, que son subjetivos, y los juicios sobre como las personas deben ser tratadas entre ellas mismas y por el Estado, que son objetivos. El liberal puede exigir objetividad sobre qué tipo de Estado quiere y mantener al mismo tiempo la subjetividad en la moral privada.

De ahí que algunos liberales, como Joseph Raz, aboguen por una distinción según la cual los juicios sobre como uno debe vivir su vida son objetivos, sin que ello autorice al Estado a imponerlos, aunque si justifique por ejemplo que subvencione más determinadas manifestaciones culturales, como la ópera y no el rock duro. Eso permite afirmar que algunas formas de vida son mejores que otras y reconocen la importancia de fomentar determinadas condiciones sociales que faciliten llevar mejores vidas, pero eso no permite la imposición de tales vidas desde el Estado, tan sólo posibilitarlas en un clima de libertad liberal. La razón es que el liberalismo no admite que exista un modo de vida que sea uniformemente el mejor para todos. Incluso a cada persona se le presentan delante una pluralidad de modos de vida, todos ellos dignos e incompatibles entre sí. El valor objetivo que los liberales quieren defender es que cada individuo elija por sí mismo. Del hecho de que mis elecciones puedan ser erróneas no se desprende que el Estado esté autorizado a imponerme una vida mejor contra mi decisión. ${ }^{30}$

A pesar de que la crítica del comunitarismo contra el subjetivismo liberal se recrudece, tampoco el liberalismo objetivista se salva de ella, ya que éste no contempla la posibilidad de que el Estado intervenga, en el caso de que una comunidad se haya propuesto unos fines comunes, cuyo logro requiere una determinada configuración legislativa. No es que el Estado asuma un papel intervencionista, sino que es la propia comunidad la que exije que se tengan en cuenta su elección de valores también en la vida pública y no sólo en la esfera privada.

Todo ello conecta con el punto siguiente. Para los liberales, el Estado debe ser neutral con respecto a los valores morales, secular y laico, sin tomar parte ideológica, simplemente garantizando la libertad de expresión. Así para Rawls todos los valores compiten en pie de igualdad, mientras que para Sandel podría haber unos valores más valiosos que otros. La política, el Estado debería fomentar esos valores, promover la virtud através de la educación y excluir los que sean peores.

5. El antiperfeccionismo y la neutralidad. El modo en el que el comunitarismo y el liberalismo se enfrentan ante el hecho del pluralismo, que ambos reconocen, es diametralmente opuesto. En el caso rawlsiano, en la esfera pública se deben encontrar criterios unitarios y reservar a la esfera privada la práctica de las distintas concepciones de la moral. En el caso de los comunitaristas, esto es una ficción irrealizable desde el momento en que determinadas visiones morales incluyen como parte de esa ética una visión global del individuo, en el que no se puede escindir sus actuaciones y elecciones públicas de sus concepciones éticas. Ello

30 DIAZ PINTOS, G. Autonomia y patemalismo. Albacete: Universidad Castilla-La Mancha, 1993. 
ataca directamente el principio liberal de una pretendida neutralidad del estado y de las leyes.

En el fondo y en la forma, Rawls pretende establecer una justicia meramente procedimental o formal que no haga alusión a los contenidos o a los resultados que se deriven del proceso democrático, con tal de que se respeten los dos principios de justicia.

Los comunitaristas consideran que ello es insuficiente ya que es inevitable hacer referencia a una moral sustantiva que impregna también en buena medida la esfera política.

Sandel pone en entredicho que en el sistema de Rawls sea posible una sociedad unitaria con unos fines comunes, sin unos valores preferentes. Así habria algunas concepciones del bien que.desaparecerian porque por ejemplo son más costosas económicamente (el arte, la pintura, el patrimonio artístico, la opera, la literatura, idiomas minoritarios). La civilización no cabe en un estado neutro porque la cultura está subvencionada por el Estado. Si se desea preservar la opera todos contribuyen con los impuestos de todos, aunque la mayoría prefirieran asistir a espectáculos de rock duro.

El perfeccionismo aristotélico considera que el éstado debe inculcar la virtud o por lo menos unos valores racionales; una vida buena racional, por tánto la concepción formal de la justicia no es suficiente. Rawls defiende una concepción deontológica de la justicia identificada con lo correcto, right, en la que se prioriza lo correcto sobre lo bueno. Los comunitaristas apuestan por una concepción teleológica o finalista de la justicia, basada en la búsqueda del bien, good.

En el primer principio cabe una posición objetiva, pero tolerante, que quiere en todo caso convencer pero racionalmente, sin imposiciones. Un liberal podría tener una concepción objetiva de la ética, respetando a su vez el principio de autonomia. Pero no es este el punto de vista de Rawls ya que prescinde de los resultados.

Sandel critica a Rawls su incoherencia, porque la posición original implica un normativismo sustantivo que incluye los principios o valores de igualdad y libertad. Y en realidad el admitir como primer valor el de la autonomía de la voluntad significa que el liberalismo no es neutral, porque presupone un yo kantiano.

Por otra parte, al priorizar la libertad y la autonomía como primer valor parece que se prescinde de los resultados o del contenido que en el desarrollo de esas capacidades se atribuya a las decisiones políticas. Rawls debería demostrar que esto es así y no darlo por supuesto.

El comunitarismo contrapone como valor la heteronomía, la dependencia del individuo con respecto a su grupo social. Ello le impone unos deberes que condicionan la vida politica, cuyos horizontes no terminan en un mero respeto de unos por otros, o en los dos principios de la justicia rawlsianos, sino que van más allá.

En cuanto a las repercusiones que ésta discusión alcanza en la práctica política y judicial, Sandel nos ofrece una maestra sintesis en su artículo "The Political Theory of the Procedural Republic". En otros términos, la pugna enfrenta a las teorias liberales basadas en los derechos, en ocasiones llamados rights foundationalist, y los comunitaristas, cuya teoria retoma el Republicanismo civico. Para no 
caer en equívocos, precisemos que es precisamente la teoría liberal a la que Sandel califica de Republicanismo procedimental (que equivaldria en términos más actuales para nosotros a la democracia formal o procedimental) como contrapuesto al republicanismo cívico defendido por los comunitaristas, que se aproxima a la democracia sustantiva.

Los liberales afirman que el estado no debe imponer a sus ciudadanos un tipo de vida preferente, sino que debe dejarles lo más libres que sea posible para que elijan sus propios valores y fines, compatible con la misma libertad para los otros. Así los liberales distinguen entre permitir y alabar. Por ejemplo, que el estado permita la pornografia no significa que la fomente. Los conservadores a veces no entienden esta distinción y creen que el permitir una situación es equivalente a estar de acuerdo con ella, cuando los liberales contraatacan afirmando que a ellos tampoco les gusta la pornografía, pero que es necesario el valor de tolerancia, la libertad de elección, o incluso respetar los procesos correctos. El hecho es que los liberales priorizan la tolerancia y la libertad de elección por encima de cualquier otro valor. La respuesta se basa en la defensa de cierto relativismo o subjetivismo moral, que impediria legislar la moralidad. Para ellos no habría un criterio para distinguir qué es buena literatura y qué es basura. El problema sobretodo consistiría en quién está autorizado a decidirlo. Según Sandel los liberales caen aquí en una contradicción in terminis, ya que la elección de los valores de tolerancia, libertad y justicia supone un juicio de valor, que ellos se han considerado capacitados a realizar, pretendiendo que no es algo meramente subjetivo, para lo que abandonan el relativismo inicial. Por la misma razón otros se creen capaces de emitir un juicio sobre qué es buena literatura y cuál no.

Las principales bases morales del planteamiento liberal se remontan al utilitarismo de John Stuart Mill o al formalismo kantiano.

No sólo para Sandel, sino también para Dworkin y Rawls el utilitarismo ofrece una fundamentación inadecuada de los principios liberales. ${ }^{31}$ De ahí que el kantismo ofrezca una base más sólida para defender la autonomía y dignidad de cada individuo, que posibilita una defensa de los derechos individuales.

La crítica kantiana del empirismo y del utilitarismo es retomada hoy por los liberales en favor de una ética que tome los derechos más en serio, parafraseando el ya tan manido título dworkiano, taking rights seriously. Según su opinión ciertos derechos son tan fundamentales que no pueden ser refutados apelando al bienestar general. Estos derechos no deben ser sometidos al pacto, al consenso, al cálculo de los intereses sociales o a la negociación politica.

En resumen los liberales kantianos hablan de los derechos, sin priorizar ninguna concepción particular del bien, de manera que no se presuponga que un tipo de vida es superior a otro. Esto se lleva cabo buscando una justificación neutral sobre los fines. Obviamente Sandel plantea sus dudas sobre cómo alcanzar este equilibrio malabar entre la afirmación de ciertas libertades y derechos como fundamentales y al mismo tiempo evitar cualquier toma de posición sobre la vida

31 Nos llevaría muy lejos justificar aquí este punto. En todo caso como el propósito del presente artículo es mostrar las diferencias entre comunitaristas y los principales liberales, el rechazo del utilitarismo es más un punto en común, que una diferencia. 
buena o sin que unos fines prevalezcan sobre otros. La conclusión es que afirmar los principios liberales, rechazando cualquier fin particular, conduce nuevamente al relativismo ético.

Ese es el origen de la distinción entre the right y the good, entre una base de derechos básicos y las concepciones del bien que la gente elige dentro de esa estructura formal. Por ejemplo, es diferente afirmar la libertad de expresión como un derecho, a afirmar que una vida de discusión política es inherentemente más digna que una vida interesada y relacionada con los asuntos públicos.

La neutralidad del Estado no es siempre posible. A la hora de legislar no es lo mismo admitir la monogamia que la poligamia o legalizar sólo las relaciones heterosexuales o las homosexuales. El Estado no puede evitar hacer juicios sobre las distintas formas de vida. Aunque declaremos que debe ser neutral, en la práctica eso es imposible, y en ocasiones ni siquiera es deseable. Por otra parte, determinadas comunidades desean que sus opciones culturales estén protegidas por la legislación; ese es el caso de las comunidades bilingües o la salvaguarda de culturas minoritarias o en peligro de extinción. La conclusión comunitarista será que es más coherente reconocer estos hechos y actuar de acuerdo con sus implicaciones.

La posición de Dworkin es más difícil de situar, ya que aunque es un liberal rights foundationalist, defiende una democracia sustantiva, es decir, no basta respetar el proceso democrático, también está atento a los contenidos atribuidos a los derechos. La diferencia está en el sistema como según los comunitaristas y según Dworkin hay que dotar de contenido a los derechos.

En este contexto resulta enormemente ilustrativo la obra de Dworkin Foundations of Liberal Equality, recientemente traducida al español. Ya desde su obra Law's Empire y su artículo en 1989, Dworkin ha ido perjeñando sus conceptos de comunidad liberal y de integridad, que en mi opinión han sido elaborados en discusión con los comunitaristas.

En esta obra el mismo Dworkin reconoce su propia evolución y un distanciamiento interesante con respecto a la radical neutralidad del Estado, defendida, por ejemplo, en A Matter of Principle.

También en Dworkin cierta concepción del bien, ideales de libertad e igualdad. Más cercano al comunitarismo en la relación entre la ética y la moral y en la crítica del principio de neutralidad de Rawls, pero su concepto de integración es para los comunitaristas insuficiente. Para comprobarlo es muy significativa la discusión con Sandel a raiz de la sentencia Bowers versus Hardwick relativa a la homosexualidad. ${ }^{32}$

Por otra parte, también Habermas ha tenido en cuenta algunas de las propuestas comunitaristas que discute en su último libro. Se acerca al comunitarismo al reconocer la identidad del individuo como algo situado, la tradición, la historia y el derecho a la nacionalidad.

Sin embargo vuelve a la defensa de una democracia procedimental, basada en la comunicación y en el diálogo. Es evidente en esta obra la influencia de los últi-

32 DWORKIN, R. "Liberal Community". op. cit., y SANDEL, M. "Moral argument and liberal toleration: Abortion and Homosexuality", op. cit. 
mos debates, que están teniendo lugar en ámbito anglo-americano, con un intento de sintetizar el paradigma liberal o procedimental con el paradigma del republicanismo civico. Es imposible hacer referencia ahora a esta discusión, por otra parte bastante desconocida en Europa. ${ }^{33}$

Ha quedado apuntado también como las ideas comunitaristas se reflejan en los últimos artículos de RawIs, en su teoría del bien y en su concepto de las virtudes públicas, a pesar de que sigue manteniendo un planteamiento formalista.

Para finalizar, señalar que en alguno de los autores comunitaristas se produce, entre otras, la siguiente paradoja; mientras que el comunitarismo denuncia al liberalismo porque su formalismo conduce en definitiva al relativismo ético, ante el binomio universalismo-multiculturalismo da la impresión de que es el propio comunitarismo quien se ve envuelto en las mismas redes, por un camino diferente.

Algunos de los problemas serios, que se reflejan en la entrevista con Taylor, son ciertas ambigüedades que dejan en el aire cuál es el lugar para el universalismo en el comunitarismo. Un yo tan situado y dependiente del contexto social, resulta manipulable si no posee un criterio externo de crítica de la sociedad dada en la que le ha tocado vivir.

La superación del subjetivismo queda inmersa o puede quedar inmersa en algunos comunitaristas en un historicismo, aunque tampoco esto es una sorpresa si atendemos a la formación hegeliana de Taylor.

En la discusión del universalismo frente al relativismo ético, no es exacto identificar el comunitarismo y el liberalismo con una de ellas de un modo global. En una versión que es de contraposición entre el universalismo y el multicultura'lismo, atribuiríamos al liberalismo la idea de universalidad y al comunitarismo cierto relativismo cultural. En contraste con lo dicho los términos se invierten si nos referimos a la fundamentación ética; el comunitarismo tiende a una fundamentación objetiva de la ética, que permitiría la universalidad de unos derecho sustantivos y la objetividad del bien, mientras que el formalismo ético del liberalismo, recurre al consenso para determinar el contenido de los valores, incurriendo en un tipo de relativismo ético. ¿Es alguno de ellos coherente? Cierta defensa de la neutralidad por parte de algunos liberales conduciría al relativismo ético, ya que unos valores formales o unos derechos que se dicen universales pero sometidos al consenso político terminan con el pretendido universalismo. Por otra parte cierto comunitarismo terminaria en el historicismo, en el relativismo cultural o en el nacionalismo.

Justificar esta afirmación y contestar a este interrogante son tareas que exceden del propósito del presente artículo. Por mi parte se constituyen como objeto de una reflexión ya iniciada. Esperemos que el lector la realice por sí mismo a través de la lectura de los materiales aquí someramente presentados.

33 Sus raíces se remontan a la llustración. Para la interpretación de esos dos paradigmas y su origen ilustrado sirva de orientación la reseña que se incluye en este Anuario de Filosofia del Derecho sobre el libro de CANEL. $\mathrm{M}^{\mathbf{3}} \mathrm{J}$. La opinión publica en la llustración escocesa. Pamplona: EUNSA, 1993 y ELOSEGUI, M. "EI derecho del ciudadano a la participación en la vida politica en Hume y la llustración escocesa". Anuario de Filosofia del Derecho. VII, 1990, p. 431-453. MICHELMAN, F. "Law’s Republic". The Yale Law Journal, v. 97, n. 8, July 1988, p. 1493-1597. 